\title{
Adjuvant Chemotherapy Improves Survival in Stage III Gastric Cancer after D2 Surgery
}

\author{
Shin-Chun Chang1, Keng-Hao Liu ${ }^{1}$, Chia-Yen Hung ${ }^{2,3}$, Chun-Yi Tsai ${ }^{1}$, Jun-Te Hsu ${ }^{1}$, Ta-Sen Yeh${ }^{1}$, Jen-Shi \\ Chen², Yung-Chia Kuo ${ }^{2}$, Yu-Shin Hung'2, Wen-Chi Chou ${ }^{2}, 4 \bowtie$ \\ 1. Department of Surgery, Chang Gung Memorial Hospital at Linkou, 5 Fu-Hsing Street, Kwei-Shan Shiang, Taoyuan, Taiwan; \\ 2. Department of Hematology and Oncology, Chang Gung Memorial Hospital at Linkou, 5 Fu-Hsing Street, Kwei-Shan Shiang, Taoyuan, Taiwan; \\ 3. Department of Hema-Oncology, Division of Internal Medicine, Mackay Memorial Hospital, Taipei, Taiwan; \\ 4. Graduate Institute of Clinical Medical Sciences, College of Medicine, Chang Gung University, Taoyuan, Taiwan. \\ $\triangle$ Corresponding author: Wen-Chi Chou, MD, Department of Hematology and Oncology, Chang Gung Memorial Hospital, 5 Fu-Hsing Street, Kwei-Shan \\ Shiang, Taoyuan, Taiwan. Tel: 886-3281200 Ext 2517 Fax: 886-3-3285818 E-mail: wenchi3992@yahoo.com.tw \\ () Ivyspring International Publisher. This is an open access article distributed under the terms of the Creative Commons Attribution (CC BY-NC) license \\ (https://creativecommons.org/licenses/by-nc/4.0/). See http://ivyspring.com/terms for full terms and conditions.
}

Received: 2017.07.18; Accepted: 2017.10.09; Published: 2018.01.01

\begin{abstract}
Background: Stage III gastric cancer is characterized by locally advanced disease with varying anatomic extent as measured by the $7^{\text {th }}$ edition of the American Joint Committee on Cancer (AJCC) staging system. There are no prognostic factors specifically identified in patients with stage III gastric cancer following extended lymph node dissection (D2) surgery.

Materials and Methods: From 2007 to 2014, 534 patients with stage III gastric cancer underwent radical gastrectomy and D2 dissection at the Chang Gung Memorial Hospital. Patients' characteristics and the impact of adjuvant chemotherapy were analyzed using univariate and multivariate analyses to identify variables associated with overall survival (OS) and disease-free survival (DFS).

Results: There were 320 deaths $(60.0 \%)$ and 284 recurrences $(53.2 \%)$ by the end of the study. The median OS and DFS were 30.7 months (95\% confidence interval [CI]: 27.5-33.9) and 26.4 months (95\% $\mathrm{Cl}$ : 21.2-31.6), respectively. The multivariate analysis identified 7 variables that were independent prognostic factors both for OS and DFS including ratio of metastatic lymph nodes to total resection lymph nodes, carcinoembryonic antigen level, Eastern Cooperative Oncology Group performance status, gastrectomy method, vascular invasion, surgical margin, and adjuvant chemotherapy. Patients with stage IIIA-IIIC disease who received adjuvant chemotherapy had better OS and DFS outcomes than those who did not.

Conclusions: Our study identified several independent prognostic factors that might help determine the appropriate counseling patients following surgical treatment. D2 surgery alone was inadequate to achieve long-term survival. As the only correctable independent prognostic factor, postoperative adjuvant chemotherapy should be recommended for eligible patients with stage III gastric cancer.
\end{abstract}

Key words: stage III gastric cancer, survival outcome, prognostic factor, adjuvant chemotherapy.

\section{Introduction}

Gastric cancer is the fourth most diagnosed cancer and the third leading cause of cancer death worldwide. ${ }^{1,2}$ Radical surgery remains the gold standard of curative treatment for patients with resectable gastric cancer, ${ }^{3}$ and together with extended lymph node dissection (D2), radical surgery is the standard surgical modality for locally advanced gastric cancer in Asian countries. ${ }^{4}$ However, approximately $25 \%-40 \%$ of patients experience tumor recurrence within 5 years after surgery, and the survival outcome worsens with stage advancement. ${ }^{5-8}$ Because the poor outcome with surgery alone, a multidisciplinary treatment includes perioperative chemotherapy and radiation therapy that are commonly implemented in patients with locally advanced diseases. ${ }^{9,} 10$

The American Joint Committee on Cancer (AJCC) staging system is based on the anatomic extent 
of the cancer and is widely used for predicting survival outcome in various types of cancer. ${ }^{11}$ According to this system, stage III gastric cancer is characterized by locally advanced disease with varying anatomic extent ranging from tumor invasion into the muscularis propria (T2-classification) to adjacent structures (T4-classification) and from no lymph node metastasis (N0-classification) to 7 or more regional lymph node metastases (N3-classification). ${ }^{11}$ Stage III gastric cancer is classified into stage IIIA, IIIB, and IIIC disease. Beyond the anatomic extent, other important clinicopathological factors associated with survival outcome after gastric cancer surgery include histological grade ${ }^{12}$, surgical margin ${ }^{13,14}$ and lymph node ratio ${ }^{12,15-19}$; however, these are not included in the AJCC staging system. Furthermore, the value of adjuvant chemotherapy for gastric cancer has been proven by two phase III studies that demonstrated a survival benefit in patients who received adjuvant therapy compared with those that did not.20, 21 However, debate surrounding the value of adjuvant chemotherapy in stage III gastric cancer continues due to the marginal statistical survival difference in subgroup analysis of patients with stage III disease in these two studies. Additionally, very few patients with extreme locally advanced disease (metastases in 15 or more regional lymph nodes) were included, ${ }^{20}$ or were completely excluded. ${ }^{21}$ As a result, the benefit of adjuvant therapy in patients with stage III gastric cancer in routine clinical practice remains to be investigated.

Because of sub-optimal survival outcomes and lack of standard treatment consensus in stage III gastric cancer, the identification of patients in high-risk groups for tumor recurrence might help to determine the appropriate counseling for patients following surgical treatment. To the best of our knowledge, there are no well documented prognostic factors specifically identified in patients with stage III gastric cancer following D2 radical surgery. This study aimed to evaluate the clinical variables relevant to overall survival (OS) and disease-free survival (DFS) in patients with stage III gastric cancer following D2 lymph node dissection.

\section{Material and Methods}

\section{Patients and Treatment}

In total, 534 consecutive patients with stage III gastric cancer underwent radical gastrectomy and D2 lymph node dissections between 2007 and 2014 at the Chang Gung Memorial Hospital (Linkou Branch) and were enrolled in this study. The diagnosis for stage III disease was defined according to the $7^{\text {th }}$ edition AJCC staging system by pathologic examination. Patients who had recurrent tumors, metastatic tumors, macroscopic residual tumors, or previously received chemotherapy or radiotherapy were excluded. The decision on a total or subtotal gastrectomy was made by the surgeon based on tumor location, histology and resection margin. All patients were advised to receive adjuvant chemotherapy within 6 weeks after radical surgery. However, the final decision on whether or not to receive such therapy was made by the patient. The regimen of adjuvant chemotherapy was fluorouracil-based, including intravenous 5-fluorouracil (5FU), 22 titanium silicate (TS)-1, 20 uracil-tegafur (UFT), ${ }^{23}$ or oxaliplatin plus capecitabine (XELOX), ${ }^{21}$ and was determined by the physicians. 5-fluorouracil or XELOX was administered for 6 months, while UFT or TS- 1 was administered for up to 1 year. Patients were categorized into adjuvant chemotherapy or non-adjuvant chemotherapy groups based on whether they received adjuvant chemotherapy for $\geq 2$ weeks or observational treatment following radical surgery. Patient characteristics were analyzed to identify the variables associated with survival outcome. The study was approved by the institutional review board, in compliance with the Helsinki Declaration (1996).

\section{Data Collection and follow up}

The administrative and clinical data included preoperative clinical features such as age; sex; Eastern Cooperative Oncology Group performance (ECOG) status; American Society of Anesthesiologists (ASA) score; history of previous cancer; preexisting comorbidities; stump cancer; family history of gastric cancer; body mass index (BMI); carcinoembryonic antigen (CEA) level, Cancer Antigen 19-9 (CA19-9) level; pathological results including Helicobacter pylori infection; microscopic surgical margin; perineural invasion; lymphatic invasion; vascular invasion; Lauren classification; total numbers of lymph node retrieval; ratio of metastatic lymph nodes to total retrieved lymph nodes (LNR); tumor (T) and nodal $(\mathrm{N})$ classification of the $7^{\text {th }}$ edition AJCC staging system. Data were recorded by the primary care clinicians using an electronic patient record form at the time of cancer diagnosis, upon cancer surgery and after final pathologic examination, if available. Comorbidities were recorded using the modified Charlson Comorbidity Index $(\mathrm{CCI})^{24}$, excluding patient age and diagnosis of cancer. The OS and DFS were calculated from the time of surgery to the time of death and tumor recurrence, respectively. The dates of surgery, tumor recurrence, and death of each patient were obtained from the institutional cancer 
center registry or the National Register of Death Database in Taiwan. All the included patients were followed until the date of death or June 30, 2016.

\section{Statistical analysis}

Basic demographic data were summarized as $n$ (\%) for categorical variables and means with 95\% confidence interval (CI) for continuous variables. Distribution of clinical variables was tabulated as $n$ (\%) and compared between groups using the Pearson chi-square test. Possible clinical and pathologic variables for survival outcome after gastric cancer diagnosis were examined by univariate and multivariate logistic regressions. Variables with $\mathrm{P}$ values $<0.10$ in univariate analysis were included for

A
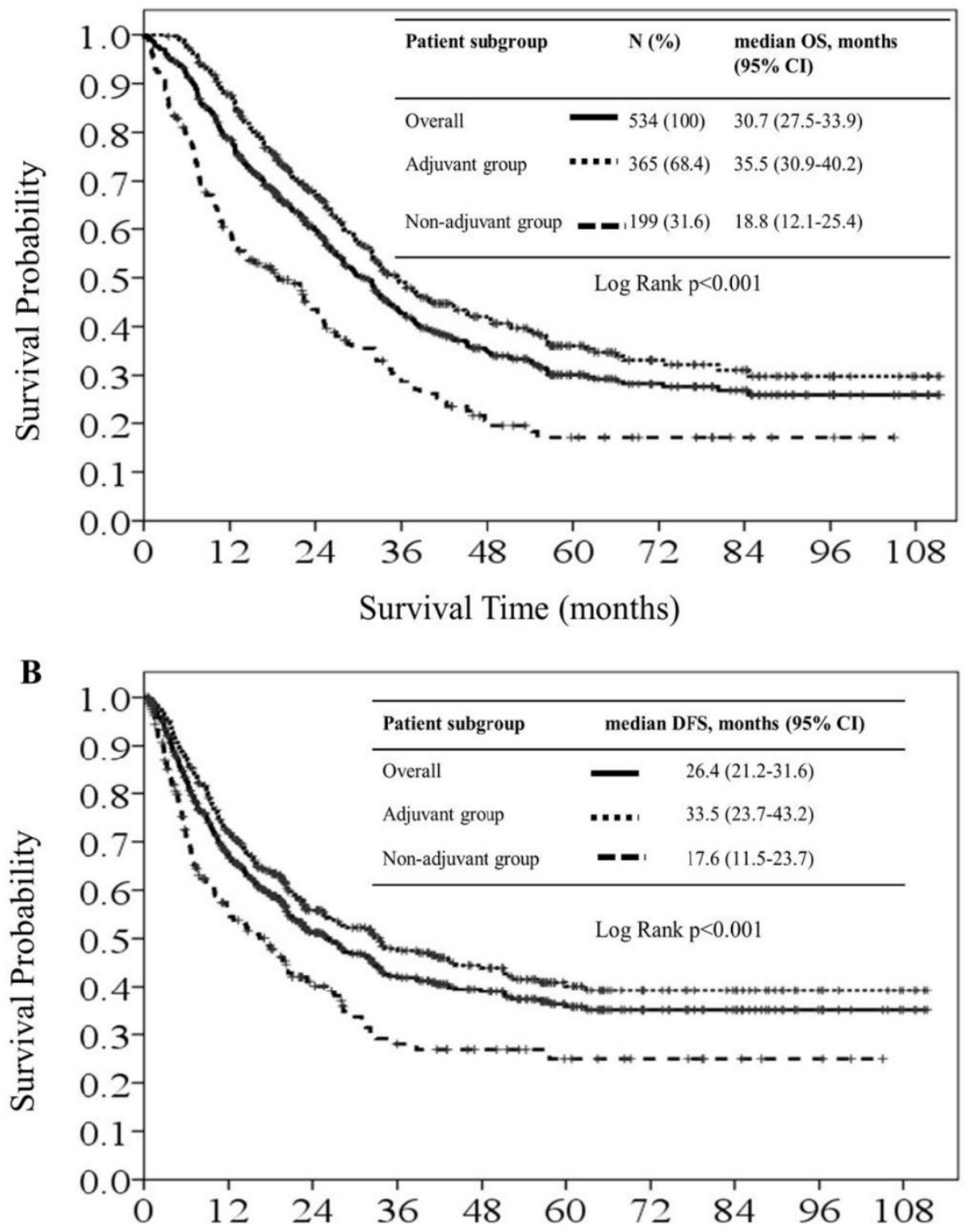

Survival Time (months)

Figure 1. Kaplan-Meier overall survival curves (IA) and disease-free survival curves (IB) for all patients, patients in the adjuvant chemotherapy group and patients in the non-adjuvant chemotherapy group. analysis in the multivariate model. To prevent the interaction of N-classification and LNR during multivariate analysis, the LNR rather than the $\mathrm{N}$-classification was included based on a higher hazard ratio (HR) associated with the LNR compared to that associated with the N-classification, as identified by univariate analysis of OS and DFS. Survival time was analyzed using the Kaplan-Meier method. Log-rank tests were used to determine significant differences between the survival curves. All statistical analyses were performed using SPSS 17.0 software (SPSS Inc., Chicago, IL, USA) and a P value $<0.05$ was considered statistically significant.

\section{Results}

Table 1 presents the baseline patient demographic data. In total, $365(68.4 \%)$ and $169(31.6 \%)$ patients were categorized into the adjuvant and non-adjuvant chemotherapy groups, respectively. Patients in the non-adjuvant chemotherapy group were generally older, with higher CCIs, poorer ECOG status, higher ASA class, a higher percentage of admission from the emergency department, and a higher percentage of vascular invasion compared with patients in the adjuvant chemotherapy group. No statistical differences in gender, $\mathrm{T}$ - and N-classification, LNR, Lauren classification, elevated CEA or CA19-9 level, gastrostomy method, and surgical margin were observed between the two patient groups.

There were 320 deaths $(60.0 \%)$ and 284 recurrences $(53.2 \%)$ at the end of the study. The median OS was 30.7 months (95\% CI: 27.5-33.9) in the overall patient cohort. The median OS in the adjuvant and non-adjuvant chemotherapy groups was 35.5 months (95\% CI: 30.9-40.2) and 18.8 months (95\% CI: 12.1-25.4), respectively. The HR for median OS was 0.50 (95\% CI: 0.40-0.63; P < $0.001)$, favoring the adjuvant group (Figure 1A). For subgroup analysis based on AJCC staging, the median OS in stage IIIA, IIIB, 
and IIIC was 66.0 months, 45.2 months, and 25.3 months, respectively among patients in the adjuvant chemotherapy group. For the non-adjuvant chemotherapy group, median OS was 37.4 months, 29.1 months, and 10.5 months for stage IIIA, IIIB, and IIIC, respectively. The 5-year OS rates of patients with stage IIIA, IIIB, and IIIC disease were $52.9 \%, 40.0 \%$, and $21.0 \%$ in the adjuvant chemotherapy group; and were $30.8 \%, 24.3 \%$, and $5.7 \%$ in the non-adjuvant chemotherapy group, respectively. The HR for the comparison of adjuvant and non-adjuvant groups in the stage IIIA, IIIB, and IIIC subgroups was 0.51 (95\% CI: $0.30-0.89, \mathrm{P}=0.016$; Figure 2A), 0.57 (95\% CI: $0.38-0.87, \mathrm{P}=0.009$; Figure 2B), and 0.43 (95\% CI: $0.31-0.59, \mathrm{P}<0.001$; Figure $2 \mathrm{C}$ ), respectively, all favoring the adjuvant chemotherapy group.

Table 1. Patients' basic demographic data

\begin{tabular}{|c|c|c|c|c|c|}
\hline Variable & Category & Overall, $\mathrm{n}=534(\%)$ & $\begin{array}{l}\text { Adjuvant chemotherapy arm, } \mathrm{n} \\
=365(\%)\end{array}$ & $\begin{array}{l}\text { No adjuvant chemotherapy arm, } \mathrm{n} \\
=169(\%)\end{array}$ & P value \\
\hline Gender & Male & $344(64.4)$ & $241(66.0)$ & $103(60.9)$ & 0.25 \\
\hline \multirow[t]{2}{*}{ Age, year } & $\leq 70$ & $292(54.7)$ & $240(65.8)$ & $52(30.8)$ & $<0.001$ \\
\hline & $>70$ & $242(45.3)$ & $125(34.2)$ & $117(69.2)$ & \\
\hline \multirow[t]{3}{*}{ BMI, kg/m² } & $<18.5$ & $65(12.2)$ & $42(11.5)$ & $23(13.6)$ & 0.78 \\
\hline & $18.5-25$ & $348(65.2)$ & $239(65.5)$ & $109(64.5)$ & \\
\hline & $>25$ & $121(22.7)$ & $84(23.0)$ & $37(21.9)$ & \\
\hline Stump cancer & yes & $28(5.2)$ & $20(5.5)$ & $8(4.7)$ & 0.72 \\
\hline $\begin{array}{l}\text { Family history of gastric } \\
\text { cancer }\end{array}$ & yes & $25(4.7)$ & $20(5.5)$ & $5(3.0)$ & 0.20 \\
\hline \multirow[t]{3}{*}{ CCI } & 0 & $247(46.3)$ & $191(52.3)$ & $56(33.1)$ & $<0.001$ \\
\hline & 1 & $174(32.6)$ & $117(32.1)$ & $57(33.7)$ & \\
\hline & $>1$ & $112(21.0)$ & $57(15.6)$ & $55(32.5)$ & \\
\hline \multirow[t]{2}{*}{ Admission mode } & OPD & $400(74.9)$ & $290(79.5)$ & $110(65.1)$ & $<0.001$ \\
\hline & ER & $134(25.1)$ & $75(20.5)$ & $59(34.9)$ & \\
\hline \multirow[t]{3}{*}{ 7th AJCC Stage group } & $3 \mathrm{~A}$ & $129(24.2)$ & $94(25.8)$ & $35(20.7)$ & 0.45 \\
\hline & $3 B$ & $180(33.7)$ & $121(33.2)$ & $59(34.9)$ & \\
\hline & $3 C$ & $225(42.1)$ & $150(41.1)$ & $75(44.4)$ & \\
\hline \multirow[t]{3}{*}{ T-classification } & $\mathrm{T} 2$ & $18(3.4)$ & $11(3.0)$ & $7(4.1)$ & 0.60 \\
\hline & $\mathrm{T} 3$ & $171(32.0)$ & $123(33.7)$ & $48(28.4)$ & \\
\hline & $\mathrm{T} 4$ & $345(64.6)$ & $231(63.3)$ & $114(67.5)$ & \\
\hline \multirow[t]{5}{*}{ N-classification } & 0 & $8(1.5)$ & $5(1.4)$ & $3(1.8)$ & 0.39 \\
\hline & 1 & $54(10.1)$ & $39(10.7)$ & $15(8.9)$ & \\
\hline & 2 & $144(27.0)$ & $100(27.4)$ & $44(26.0)$ & \\
\hline & $3 \mathrm{~A}$ & $189(35.4)$ & $135(37.0)$ & $54(32.0)$ & \\
\hline & 3B & $139(26.0)$ & $86(23.6)$ & $53(31.4)$ & \\
\hline \multirow[t]{3}{*}{ LNR } & $<0.10$ & 119 (22.3) & $88(24.1)$ & $31(18.3)$ & 0.28 \\
\hline & $0.10 \sim 0.40$ & $255(47.8)$ & $173(47.4)$ & $82(48.5)$ & \\
\hline & $>0.40$ & $160(30.0)$ & $104(28.5)$ & $56(33.1)$ & \\
\hline \multirow[t]{2}{*}{ Lauren classification } & $\begin{array}{l}\text { Intestinal, mixed, or } \\
\text { unclassified }\end{array}$ & $377(70.6)$ & $262(71.8)$ & $115(68.0)$ & 0.63 \\
\hline & diffuse type & $153(29.4)$ & $99(28.2)$ & $54(32.0)$ & \\
\hline CEA, ng/dL & $>5$ & 89 (16.7) & $58(15.9)$ & $31(18.3)$ & 0.48 \\
\hline CA19-9, ng/dL & $>37$ & $87(16.3)$ & $54(14.8)$ & $33(19.5)$ & 0.17 \\
\hline \multirow[t]{2}{*}{ ECOG status } & $0-1$ & 388 (72.7) & $294(80.5)$ & $94(55.6)$ & $<0.001$ \\
\hline & $2-4$ & $146(27.3)$ & $71(19.5)$ & $75(44.4)$ & \\
\hline \multirow[t]{2}{*}{ ASA class } & 2 & $253(47.4)$ & $204(55.9)$ & $49(29.0)$ & $<0.001$ \\
\hline & $>2$ & $281(52.6)$ & $161(44.1)$ & $120(71.0)$ & \\
\hline \multirow[t]{2}{*}{ Gastrostomy method } & total & $200(37.5)$ & $133(36.4)$ & $67(39.6)$ & 0.48 \\
\hline & partial & $334(62.5)$ & $232(63.6)$ & $102(60.4)$ & \\
\hline Perineural invasion & yes & 377 (70.6) & $254(69.6)$ & $123(72.8)$ & 0.45 \\
\hline Vascular invasion & yes & $157(29.4)$ & $97(26.6)$ & $60(35.5)$ & 0.035 \\
\hline Lymphatic invasion & yes & $445(83.3)$ & $297(81.4)$ & $148(87.6)$ & 0.074 \\
\hline H. pylori infection & yes & $96(18.0)$ & $69(18.9)$ & $27(16.0)$ & 0.41 \\
\hline Surgical margin & positive & $72(13.5)$ & $43(11.8)$ & $29(17.2)$ & 0.091 \\
\hline
\end{tabular}

AJCC, American Joint Committee on Cancer; ASA, American Society of Anesthesiologists; BMI, body mass index; CA19-9, Cancer antigen 19-9; CCI, Charlson comorbidity index; CEA, carcinoembryonic antigen; ECOG, Eastern Cooperative Oncology Group; ER, emergency room; LNR, ratio of metastatic lymph nodes to total resection lymph nodes; OPD, outpatient department. 

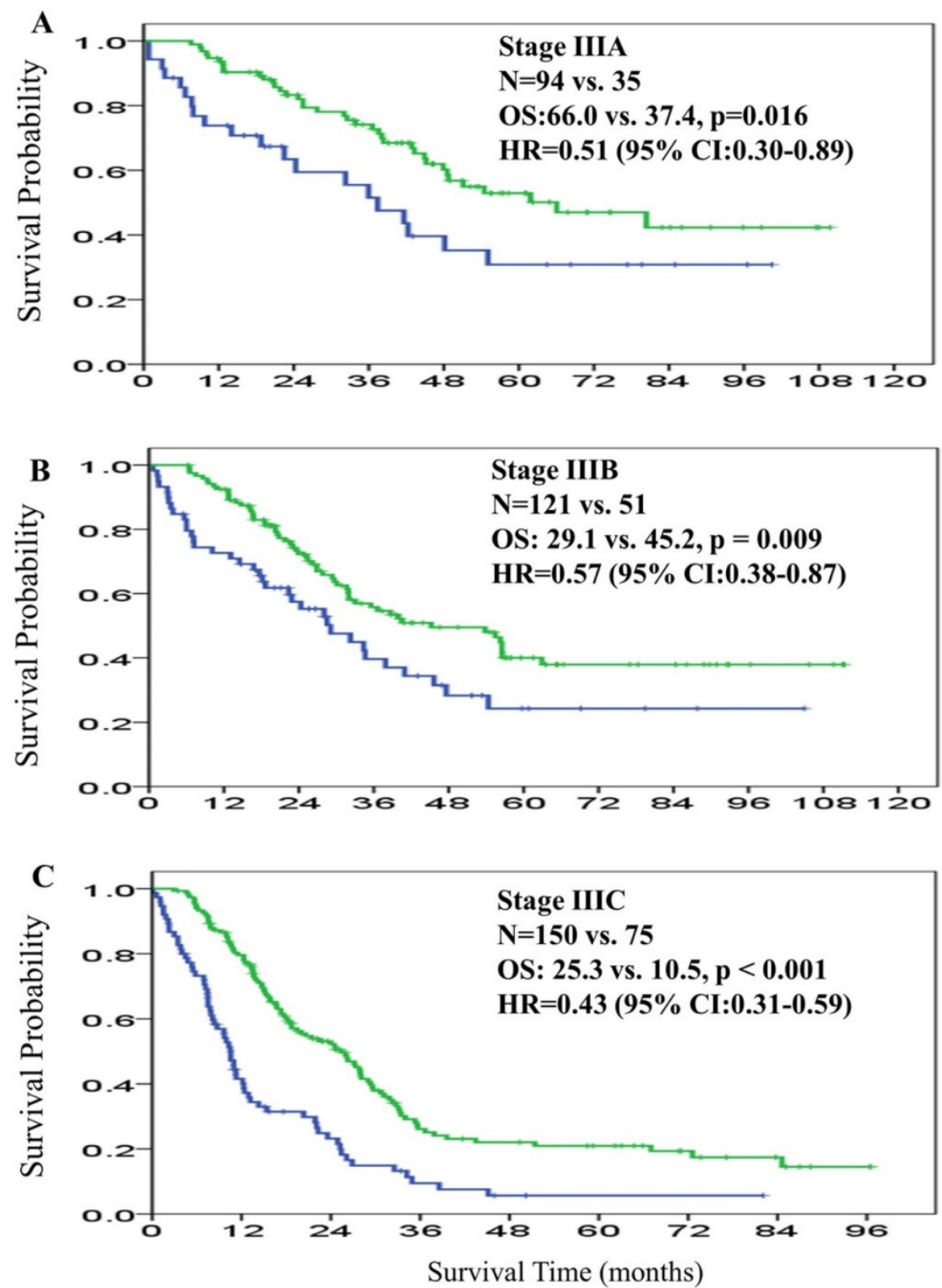

Figure 2. Overall survival curves for patients in the adjuvant chemotherapy group (green line) and patients in the non-adjuvant chemotherapy group (blue line) according to $7^{\text {th }}$ American Joint Committee on Cancer (AJCC) stage IIIA (2A), IIIB (2B), and IIIC (2C).

The overall median DFS was 26.4 months (95\% CI: 21.2-31.6) across the patient cohort. The median DFS in the adjuvant and non-adjuvant chemotherapy groups was 33.5 months (95\% CI: 23.7-43.2) and 17.6 months (95\% CI: 11.4-23.7), respectively. The HR for median DFS was 0.59 (95\% CI: 0.47-0.76; P < 0.001), favoring the adjuvant group (Figure 1B). The median DFS in stage IIIA, IIIB, and IIIC was not reached, 51.3 months, and 16.1 months among patients in the adjuvant chemotherapy group, respectively, and was 38.7 months, 28.3 months, and 7.4 months among patients in the non-adjuvant chemotherapy group, respectively. The HR for the comparison of adjuvant and non-adjuvant cohorts in the stage IIIA, IIIB, and IIIC subgroups was 0.65 (95\% CI: $0.35-1.21, \mathrm{P}=0.18$; Figure 3A), 0.68 (95\% CI: 0.44-1.08, P = 0.10; Figure
3B), and 0.51 (95\% CI: 0.37-0.71, P < 0.001; Figure 3C), respectively, all favoring the adjuvant chemotherapy group. The decreasing HR value from IIIA toward IIIC disease indicated that patients with stage IIIC disease derived more survival benefit for both OS and DFS from adjuvant chemotherapy than patients with stage IIIA or IIIB disease.

Univariate analysis of the clinical variables for predicting OS and DFS of all patients is detailed in Table 2. The OS was significantly better in female patients, patients aged $\leq 70$ years, non-stump cancer, $\mathrm{CCI}=0$, patients admitted from the outpatient department, T2-classification N0- or N1-classification, LNR $\leqq 0.10 \%, C E A \leq 5 \mathrm{ng} / \mathrm{mL}$, CA19-9 $\leq 37 \mathrm{ng} / \mathrm{mL}$, ECOG status 0-1, ASA class 2, subtotal gastrectomy, absence of perineural invasion, absence of vascular 
invasion, absence of lymphatic invasion, negative surgical margin, and in patients who received adjuvant chemotherapy. Similarly, univariate analysis identified gender, age, BMI, stump cancer, CCI, admission mode, T-classification, N-classification,
LNR, CEA level, CA19-9 level, ECOG status, gastrectomy method, perineural invasion, vascular invasion, lymphatic invasion, surgical margin, and adjuvant chemotherapy to be predictive variables of DFS.

Table 2. Univariate analysis for overall survival (OS) and disease-free survival (DFS)

\begin{tabular}{|c|c|c|c|c|c|c|}
\hline \multirow[t]{2}{*}{ Variable } & \multirow[t]{2}{*}{ Category } & \multirow[t]{2}{*}{ no $(\%)$} & \multicolumn{2}{|l|}{ OS } & \multicolumn{2}{|l|}{ DFS } \\
\hline & & & $\begin{array}{l}\text { median survival time, } \\
\text { months }(95 \% \mathrm{CI})\end{array}$ & $\mathrm{P}$ value & $\begin{array}{l}\text { median survival time, } \\
\text { months }(95 \% \mathrm{CI})\end{array}$ & $\mathrm{P}$ value \\
\hline \multirow[t]{2}{*}{ Gender } & male & $344(64.4)$ & $29.1(25.3-32.8)$ & 0.027 & $22.8(18.2-27.3)$ & 0.037 \\
\hline & female & $190(35.6)$ & $33.9(27.1-40.7)$ & & $32.4(9.3-55.6)$ & \\
\hline \multirow[t]{2}{*}{ Age } & $\leq 70$ & $292(54.7)$ & $33.0(28.6-37.4)$ & 0.022 & $25.5(18.4-32.6)$ & 0.65 \\
\hline & $>70$ & $242(45.3)$ & $26.1(20.4-31.9)$ & & $27.8(19.7-35.9)$ & \\
\hline \multirow[t]{3}{*}{ BMI } & $<18.5$ & $65(12.2)$ & $28.1(18.0-38.2)$ & 0.052 & $20.2(10.2-30.1)$ & 0.028 \\
\hline & $18.5-25$ & $348(65.2)$ & $29.1(25.7-32.5)$ & & $22.9(18.0-27.9)$ & \\
\hline & $>25$ & $121(22.7)$ & $42.3(31.7-52.9)$ & & $51.3(\mathrm{n} / \mathrm{a})$ & \\
\hline \multirow[t]{2}{*}{ Stump cancer } & no & $506(94.8)$ & $32.0(28.5-35.4)$ & 0.003 & $27.4(21.8-33.1)$ & 0.013 \\
\hline & yes & $28(5.2)$ & $22.1(15.8-28.4)$ & & $13.0(8.8-17.2)$ & \\
\hline \multirow[t]{2}{*}{ Family history of gastric cancer } & no & 509 (95.3) & $29.7(26.4-33.0)$ & 0.37 & $25.6(20.3-31.3)$ & 0.57 \\
\hline & yes & $25(4.7)$ & $80.4(8.8-151.9)$ & & $51.2(0-109.4)$ & \\
\hline \multirow[t]{2}{*}{ CCI } & no & $247(46.3)$ & $38.3(29.5-47.2)$ & $<0.001$ & $33.9(16-5-51.2)$ & 0.003 \\
\hline & yes & $287(53.7)$ & $24.3(21.8-26.9)$ & & 20.5 (13.9-26.9) & \\
\hline \multirow[t]{2}{*}{ Admission mode } & OPD & $400(74.9)$ & $33.9(28.5-39.3)$ & $<0.001$ & $31.5(23.4-39.7)$ & 0.003 \\
\hline & ER & $134(25.1)$ & $25.5(20.1-30.9)$ & & $16.7(11.8-321.6)$ & \\
\hline \multirow[t]{3}{*}{ T-classification } & 2 & $18(3.4)$ & $61.9(27.1-96.6)$ & $<0.001$ & $33.5(\mathrm{n} / \mathrm{a})$ & $<0.001$ \\
\hline & 3 & $171(32.0)$ & $42.3(33.4-51.1)$ & & $\mathrm{n} / \mathrm{a}$ & \\
\hline & 4 & $345(64.6)$ & $24.9(21.1-28.8)$ & & $18.9(15.6-22.4)$ & \\
\hline \multirow[t]{4}{*}{ N-classification } & $0-1$ & $62(11.6)$ & $48.6(36.3-60.8)$ & $<0.001$ & $62.9(\mathrm{n} / \mathrm{a})$ & $<0.001$ \\
\hline & 2 & $144(27.0)$ & $42.9(25.9-59.8)$ & & $\mathrm{n} / \mathrm{a}$ & \\
\hline & $3 \mathrm{~A}$ & $189(35.4)$ & $29.4(24.9-33.8)$ & & 23.1 (17.9-28.3) & \\
\hline & $3 B$ & $139(26.0)$ & $17.9(11.8-24.0)$ & & $10.9(7.2-14.7)$ & \\
\hline \multirow[t]{3}{*}{ LNR } & $<0.10$ & $119(22.3)$ & $66.0(\mathrm{n} / \mathrm{a})$ & $<0.001$ & $\mathrm{n} / \mathrm{a}$ & $<0.001$ \\
\hline & $0.10-0.40$ & $255(47.8)$ & $32.2(27.9-36.6)$ & & $28.3(21.7-35.0)$ & \\
\hline & $>0.40$ & $160(30.0)$ & $18.7(13.8-23.7)$ & & $18.7(13.8-23.7)$ & \\
\hline \multirow[t]{2}{*}{ Lauren classification } & $\begin{array}{l}\text { Intestinal type, mixed, or } \\
\text { unclassified }\end{array}$ & $377(70.6)$ & $31.7(27.4-35.9)$ & 0.16 & $31.6(18.8-44.4)$ & 0.35 \\
\hline & Diffuse type & $157(29.4)$ & $28.1(24.1-32.1)$ & & $23.9(18.9-28.9)$ & \\
\hline \multirow[t]{2}{*}{ CEA, ng/dL } & $\leq 5$ & $445(83.3)$ & $32.0(28.2-35.8)$ & 0.014 & $28.3(22.8-33.8)$ & 0.002 \\
\hline & $>5$ & 89 (16.7) & $24.3(16.9-31.7)$ & & $12.7(6.5-18.8)$ & \\
\hline \multirow[t]{2}{*}{ CA19-9, ng/dL } & $\leq 37$ & $447(83.7)$ & $32.0(28.1-35.9)$ & 0.006 & $27.7(21.6-33.8)$ & 0.034 \\
\hline & $>37$ & $87(16.3)$ & $26.1(13.4-38.8)$ & & $19.7(9.4-30.0)$ & \\
\hline \multirow[t]{2}{*}{ ECOG status } & $0-1$ & $388(72.7)$ & $36.0(31.8-40.1)$ & $<0.001$ & $33.0(23.6-42.4)$ & $<0.001$ \\
\hline & $>1$ & $146(27.3)$ & $13.2(9.5-16.9)$ & & $11.7(6.6-16.9)$ & \\
\hline \multirow[t]{2}{*}{ ASA class } & 2 & $253(47.4)$ & $33.9(28.8-39.0)$ & 0.014 & $25.5(17.9-33.1)$ & 0.96 \\
\hline & $>2$ & $281(52.6)$ & $27.7(23.3-32.2)$ & & $27.7(20.9-34.5)$ & \\
\hline Gastrectomy method & TG & $200(37.5)$ & $24.6(21.9-27.3)$ & $<0.001$ & $17.8(13.5-22.1)$ & 0.001 \\
\hline & Partial & $334(62.5)$ & $35.3(30.9-39.7)$ & & $31.8(21.9-41.6)$ & \\
\hline Perineural invasion & no & $157(29.4)$ & $42.9(30.7-55.0)$ & 0.002 & $40.6(16.5-64.8)$ & 0.031 \\
\hline & yes & $377(70.6)$ & $27.1(23.8-30.4)$ & & $22.6(18.2-27.1)$ & \\
\hline Vascular invasion & no & $377(70.6)$ & $35.6(29.8-41.3)$ & $<0.001$ & $32.4(23.5-41.4)$ & $<0.001$ \\
\hline & yes & $157(29.4)$ & $22.8(17.8-27.9)$ & & $14.9(9.7-20.1)$ & \\
\hline Lymphatic invasion & no & 89 (16.7) & $51.1(10.9-91.2)$ & $<0.001$ & $\mathrm{n} / \mathrm{a}$ & 0.002 \\
\hline & yes & $445(83.3)$ & $27.9(24.6-31.3)$ & & $22.7(18.5-27.0)$ & \\
\hline Resection margin & no & $462(86.5)$ & $33.3(29.5-37.1)$ & $<0.001$ & $29.3(23.1-35.6)$ & $<0.001$ \\
\hline & yes & $72(13.5)$ & $14.3(10.2-18.3)$ & & $12.1(7.1-17.3)$ & \\
\hline Helicobacter pylori infection & no & $438(82.0)$ & $29.3(25.8-32.9)$ & 0.13 & $25.5(20.2-30.8)$ & 0.27 \\
\hline & yes & $96(18.0)$ & $37.6(25.6-49.5)$ & & $33.9(15.9-51.8)$ & \\
\hline Adjuvant chemotherapy & no & $169(31.6)$ & $18.7(12.1-25.4)$ & $<0.001$ & $17.6(11.4-23.7)$ & $<0.001$ \\
\hline & yes & $365(68.4)$ & $35.5(30.9-40.2)$ & & $33.5(23.7-43.2)$ & \\
\hline
\end{tabular}

ASA, American Society of Anesthesiologists; BMI, body mass index; CA19-9, Cancer antigen 19-9; CCI, Charlson comorbidity index; CEA, carcinoembryonic antigen; CI, confidence interval; ECOG, Eastern Cooperative Oncology Group; ER, emergency room; LNR, ratio of metastatic lymph nodes to total resection lymph nodes; OPD, outpatient department; TG, total gastrectomy. 

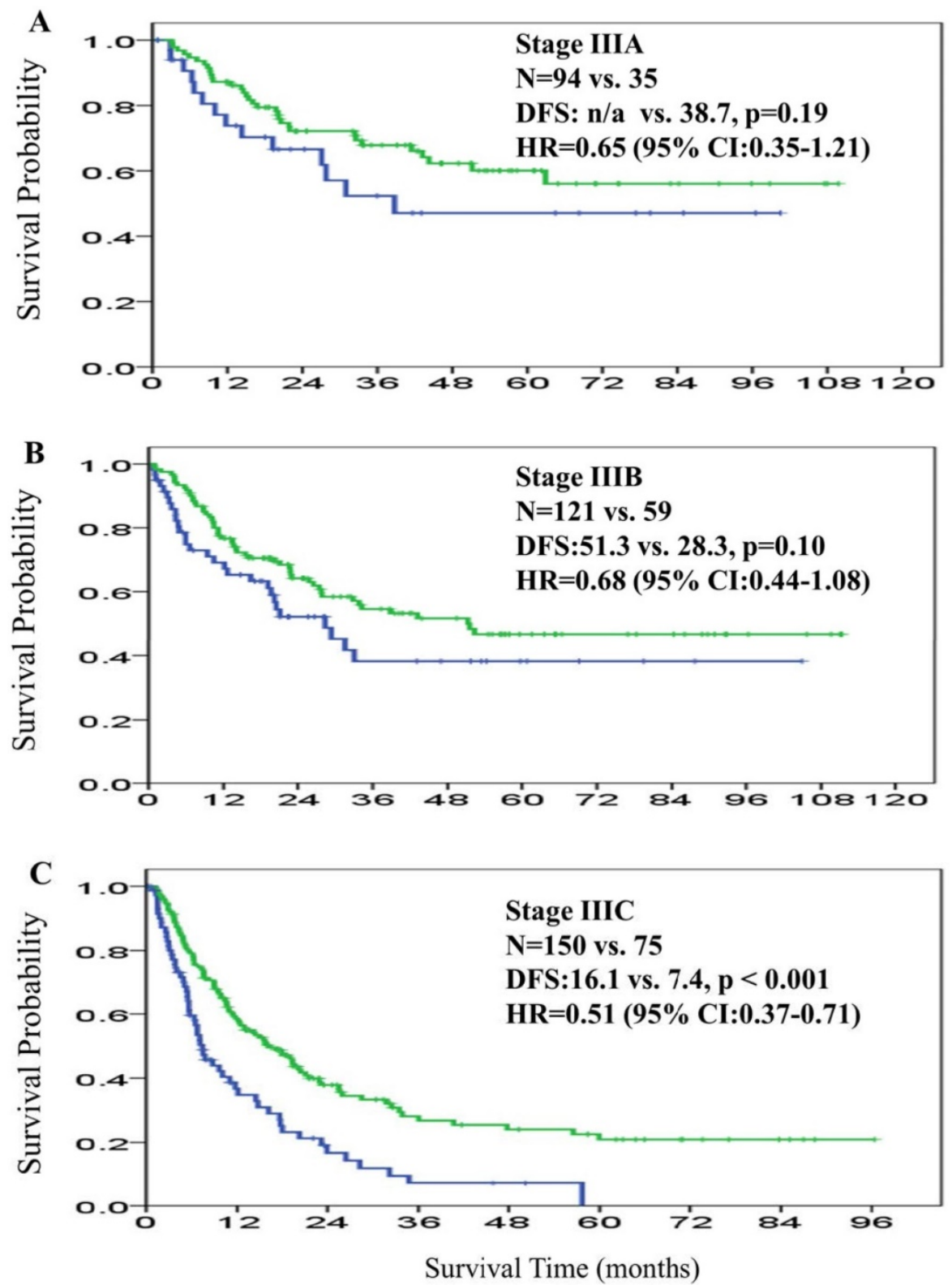

Figure 3. Disease-free survival curves for patients in the adjuvant chemotherapy group (green line) and patients in the non-adjuvant chemotherapy group (blue line) according to $7^{\text {th }}$ American Joint Committee on Cancer (AJCC) stage IIIA (3A), stage IIIB (3B), and IIIC (3C).

The multivariate analysis identified 9 variables including CCI, LNR, CEA level, ECOG status, gastrectomy method, perineural invasion, vascular invasion, surgical margin and adjuvant chemotherapy as the only independent prognostic factors for OS (Figure 4A). Except for CCI and perineural invasion, the other 7 variables were the only independent prognostic factors for DFS in multivariate analysis (Figure 4B). The adjusted HR was $0.60(95 \%$ CI: $0.56-0.90, \mathrm{P}<0.001)$ for OS and 0.68 (95\% CI: $0.53-0.88, P=0.003$ ) for DFS in patients in the adjuvant chemotherapy group compared with those in the non-adjuvant chemotherapy group.

The impact of type of adjuvant chemotherapy regimen on survival outcome was further analyzed.
Among 364 patients who received adjuvant chemotherapy, 122 patients $(33.4 \%)$ received 5FU monotherapy, 92 patients $(25.2 \%)$ received UFT monotherapy, 89 patients $(24.4 \%)$ received the XELOX regimen, 44 patients $(12.1 \%)$ received TS-1 monotherapy, and 18 patients (4.9) received other regimens. In general, patients who received any regimen of chemotherapy had better survival outcomes in terms of OS (Figure 5A) and DFS (Figure 5B) than those treated without adjuvant chemotherapy. Patients received TS- 1 had the best survival outcome in our study, though there was no statistical difference in overall survival and disease-free survival between patients receiving TS-1 or other chemotherapy regimens. 
A.

Overall Survival (multivariate analysis)

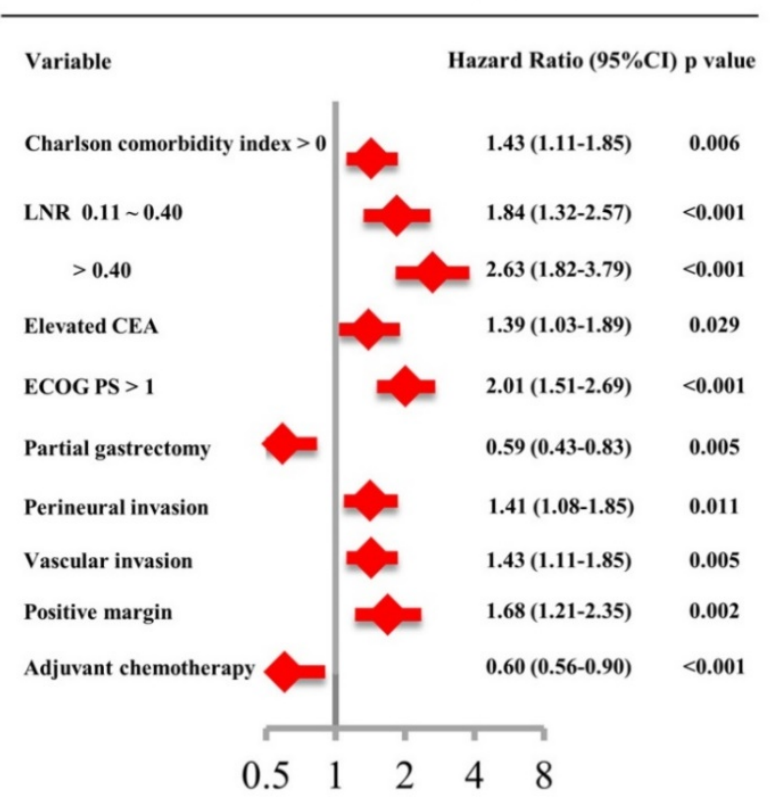

B.

Disease-free survival (multivariate analysis)

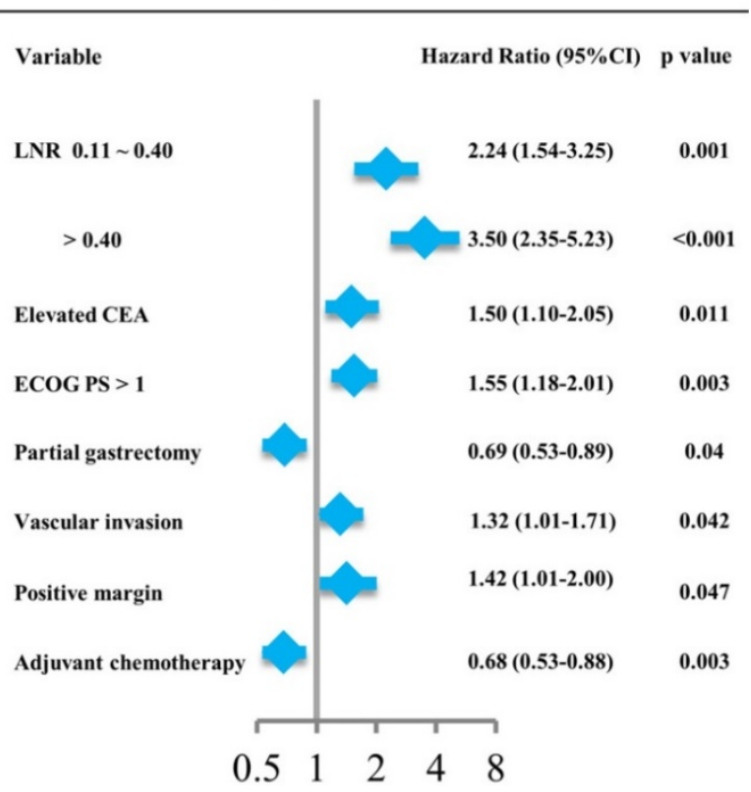

Figure 4. Multivariate analysis of patient characteristics for overall survival (4A) and disease-free survival (4B).
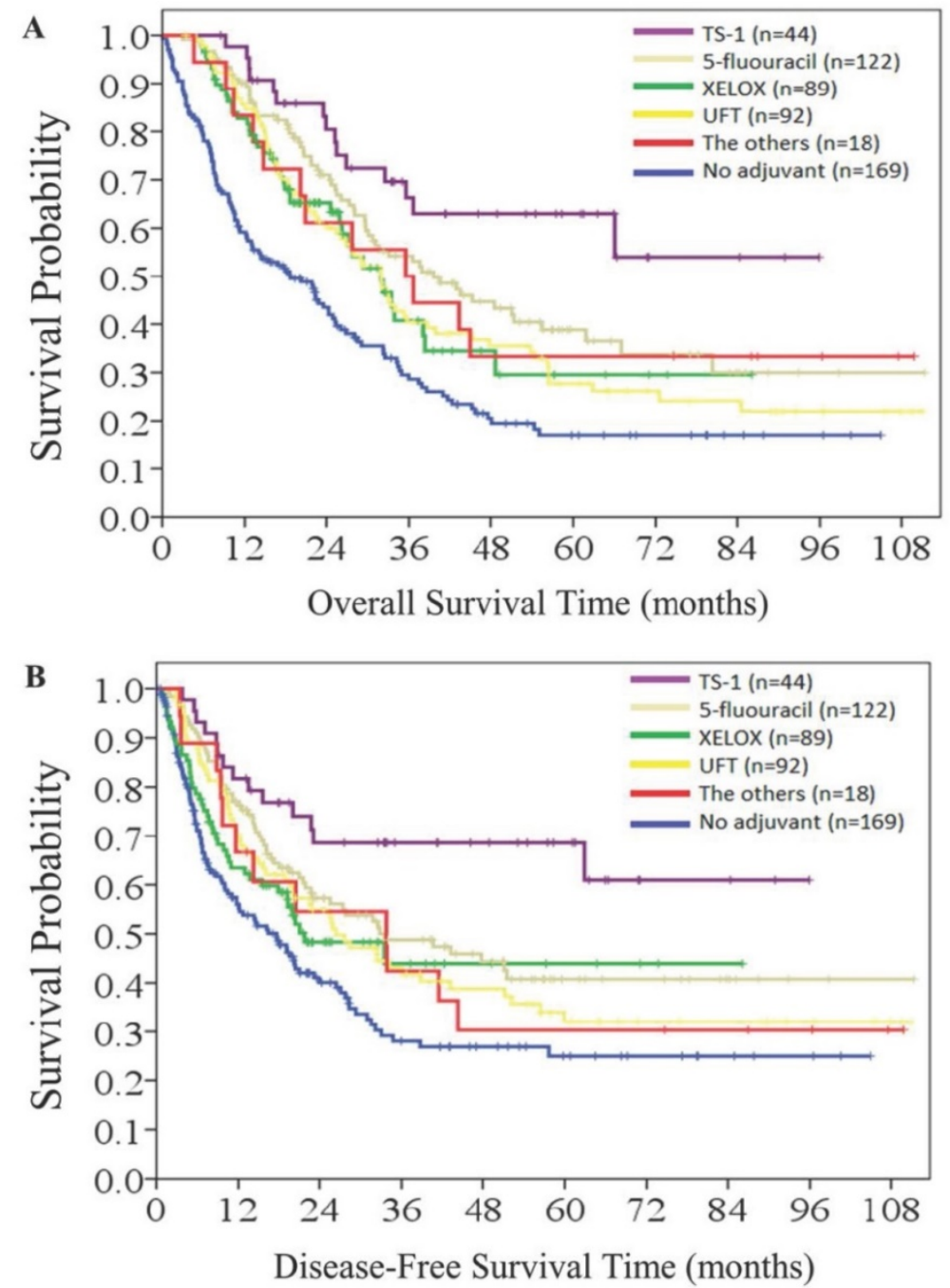

Figure 5. Overall survival $(5 A)$ and disease-free survival $(5 B)$ according to chemotherapy regimens 


\section{Discussion}

Although radical gastrectomy with D2 lymph node dissection is a prerequisite for cure of gastric cancer, the long-term oncological outcome for resected stage III gastric cancer remains sub-optimal, with a median survival of 30.7 months in our patient cohort. Because surgery alone was inadequate to achieve long-term survival in stage III gastric cancer $^{20,} 21$ identification of patients in high-risk groups for tumor recurrence might help to determine the appropriate counseling for patients following surgical treatment. Our study identified LNR, CEA level, ECOG status, gastrectomy method, vascular invasion, surgical margin, and adjuvant chemotherapy as independent factors that predicted OS and DFS. Among these seven independent prognostic factors, postoperative adjuvant chemotherapy is the only correctable factor. Patients who received adjuvant chemotherapy had better survival outcomes in terms of OS and DFS across stage IIIA to IIIC disease than those treated without adjuvant chemotherapy under any regimen. Furthermore, our results showed that patients with more advanced cancer (stage IIIC) derived greater survival benefit from adjuvant chemotherapy than patients with less advanced disease (stage IIIA or IIIB).

Not surprisingly, some prognostic factors identified in our study were well established in relation to survival outcomes in gastric cancer. For example, higher CEA level, ${ }^{25}$ positive surgical margin, 13,14 total gastrectomy, ${ }^{25}$ and presence of vascular invasion reflected the more advanced tumor stage or aggressive clinical course, while ECOG status represented patient's performance and fitness for radical surgery. ${ }^{26}$ Using the AJCC staging system, numbers of lymph node metastases were used to determine $\mathrm{N}$-classification and stage group. However, it is difficult to further distinguish survival outcome in patients beyond N3b-classification (lymph node metastatic numbers $>15$ ) using this system. Recently, the value of LNR in gastric cancer was vigorously explored. Marchet et al first reported that LNR was an independent prognostic factor in 1853 gastric cancer patients regardless of the type of lymphadenectomy. ${ }^{15}$ Subsequently, several studies demonstrated the superior value of LNR over LN metastatic numbers in prognosis after gastric cancer surgery. ${ }^{16-19}$ In line with this, our results identified LNR as a prognostic factor for survival outcome in patients with stage III gastric cancer after radical surgery.

The consensus on adjuvant chemotherapy for gastric cancer was mainly reached due to meta-analyses conducted prior to 2007.27, 28 The
Adjuvant Chemotherapy Trial of TS-1 for Gastric Cancer (ACTS-GC) was the first well-designed phase III study that showed the significant benefit of adjuvant chemotherapy for Japanese patients with stage II and III gastric cancer who had undergone D2 dissection. ${ }^{20}$ Another phase III study examining capecitabine and oxaliplatin combination treatment (CLASSIC study) in stage II-III gastric cancer after D2 resection was published in 2012 and reported positive results. ${ }^{21}$ Although consensus regarding the value of adjuvant chemotherapy was widely reached after the two phase III studies above, some debate continued. First, ACTS-GS included patients staged using the Japanese Gastric Cancer Staging system, which categorizes N-classification by anatomic location of metastatic lymph nodes rather than by numbers of lymph node metastases as in the AJCC staging system..$^{20}$ In the CLASSIC trial, the inclusion criteria included patients with $6^{\text {th }}$ edition AJCC stage II, IIIA, and IIIB, while patients with numbers of metastatic lymph nodes over 15 were excluded. ${ }^{21}$ Secondly, the statistical survival benefit was identified only in patients with stage II disease in the CLASSIC trial and patients with stage II or IIIA in the ACTS-GC study by subgroup analysis. Both studies demonstrated insignificant survival benefit of adjuvant chemotherapy versus observation in further advanced stage III disease. ${ }^{20,}{ }^{21}$ Patients received TS- 1 had the best survival outcome in our study, though there was no statistical difference in overall survival and disease-free survival between patients receiving TS-1 or other chemotherapy regimens. A patient's postoperative condition, personal finance, availability of a specific regimen and the physician's preference all contributed to the selection of different regimens. Based on these studies, the role and optimal regimen of adjuvant chemotherapy in stage III gastric cancer, especially for those with stage IIIC disease, was still uncertain. ${ }^{20,}{ }^{21}$ Prospective randomized phase III trials should be conduct to elaborate these urgent issues. In contrast to ACTS-GC and the CLASSIC trial, our study showed that adjuvant chemotherapy provided statistical benefit with regard to OS and DFS for patients with stage III gastric cancer, while the highest survival benefit was observed among patients with stage IIIC disease. The HRs were 0.60 for OS and 0.68 for DFS in our study, which were comparable to 0.67 for OS and 0.65 for DFS in the ACTS-GC study ${ }^{20}$ and to 0.58 for OS and 0.66 for DFS in the CLASSIC study, ${ }^{21}$ when comparing patients who received adjuvant chemotherapy and those who did not. Similar to our observations, Chiu et al also reported that adjuvant chemotherapy prolonged OS for patients with stage III, but not stage II disease, which is reflected in real-world cases of gastric cancer. ${ }^{29}$ The 
discrepancy between clinical trials and real-word practice may be explained by the selection bias of patient groups e.g., $27 \%$ of our patients had ECOG status 2-4 at the time of initiation of adjuvant chemotherapy in daily practice, while the CLASSIC trial and ACTS-GC study enrolled patients with ECOG status 0-1 only. 20, 21 In our stage IIIA subgroup, the 5-year OS was 53\% in the adjuvant chemotherapy group and $31 \%$ in the non-adjuvant chemotherapy group, which was worse than the CLASSIC trial (70\% and $63 \%)$ and the ACTS-GC study (67\% and 57.3\%). ${ }^{30 \text {, }}$ 31 Secondly, most of our patient cohort $(98.5 \%)$ had lymph node metastases. One meta-analysis reported that adjuvant chemotherapy provided OS benefits in gastric cancer patients with lymph node metastases but not in those without lymph node metastases. ${ }^{32}$ Similarly, patients with positive lymph node metastases derived more benefit from adjuvant chemotherapy, which was also reported in subgroup analysis in the CLASSIC trial. ${ }^{31}$

Our study identified several independent prognostic factors and demonstrates the survival benefit of adjuvant chemotherapy in patients with stage III gastric cancer after D2 lymph node dissection, especially in those with AJCC stage IIIC disease. All the data were collected from a prospectively formulated electronic record. However, there are several limitations to our study. Firstly, selection bias might exist as this was a retrospective study. Patients in the adjuvant group had better survival outcome but this may be due to younger age, excellent ECOG status, and lower comorbidities than those in the non-adjuvant group. However, the impact of adjuvant chemotherapy on survival still existed after adjustment for other confounding factors in the multivariate model. Secondly, given the study's retrospective nature and the lack of a regular image follow-up duration, the actual DFS might be overestimated in our study. Thirdly, various levels of competency among the surgeons performing the operations may also contribute to different surgical outcomes. All patients with stage III gastric cancer were advised to receive adjuvant chemotherapy within 6 weeks after radical surgery in our institute. However, the patient made the final decision on adjuvant chemotherapy. In our experiences, there were multiple factors that attributed to such decision. 33 Most of them were personal and varied from patients to patients. Unfortunately, we were not able to list all the reasons of these $31.6 \%$ patients who refused adjuvant chemotherapy. The Cancer Genome Atlas project recently identified four molecular subtypes of gastric cancer: Epstein-Barr virus (EBV), microsatellite instability (MSI), genomically stable (GS), and chromosomal instability (CIN). ${ }^{34}$ One recent study evaluated the clinical significance of these four molecular subtypes of gastric cancer and found that patients with the CIN subtype experienced the greatest benefit from adjuvant chemotherapy while those with the GS subtype had the least. ${ }^{35}$ Unfortunately, we were unable to categorize our patients according to these molecular subtypes for these features were not included at the time of diagnosis. Finally, this cohort included patients from a single center, raising questions about the generalizability of the study findings. Therefore, it is reasonable to expand the study to other high-volume centers with experience of high-quality D2 surgery.

\section{Conclusion}

Our study identified several independent prognostic factors which might help determine the appropriate counseling for patients following surgical treatment. D2 surgery alone was inadequate to achieve long-term survival for stage III gastric cancer patients. As the only correctable independent prognostic factor, postoperative adjuvant chemotherapy should be recommended for eligible patients with stage III gastric cancer.

\section{Acknowledgments}

The authors thank all the members of the Cancer Center, Chang Gung Memorial Hospital, for assisting with data collection. They would also like to extend their gratitude to Ms. Shu-Fang Huang and Ms. Vengi Ho from the Center for Clinical Research in Chang Gung Memorial Hospital for their invaluable contribution in biostatistics analysis.

\section{Competing Interests}

The authors have declared that no competing interest exists.

\section{References}

1. Ferlay J, Soerjomataram I, Dikshit R, Eser S, Mathers C, Rebelo M, Parkin DM, Forman D, Bray F. Cancer incidence and mortality worldwide: sources, methods and major patterns in GLOBOCAN 2012. International journal of cancer. 2015; 136(5):E359-386

2. Jemal A, Bray F, Center MM, Ferlay J, Ward E, Forman D. Global cancer statistics. CA Cancer J Clin. 2011;61 (2):69-90.

3. Jiang L, Yang KH, Guan QL, Zhao P, Chen Y, Tian JH. Survival and recurrence free benefits with different lymphadenectomy for resectable gastric cancer: a meta-analysis. J Surg Oncol. 2013;107(8):807-814.

4. Wu CW, Hsiung CA, Lo SS, Hsieh MC, Chen JH, Li AF, Lui WY, Whang-Peng J. Nodal dissection for patients with gastric cancer: a randomised controlled trial. Lancet Oncol. 2006;7(4):309-315.

5. D'Angelica M, Gonen M, Brennan MF, Turnbull AD, Bains M, Karpeh MS. Patterns of initial recurrence in completely resected gastric adenocarcinoma. Ann Surg. 2004;240(5):808-816.

6. Wu CW, LO SS, Shen KH, Hsieh MC, Chen JH, Chiang JH, Lin HJ, Li AF, Lui WY. Incidence and factors associated with recurrence patterns after intended curative surgery for gastric cancer. World J Surg. 2003;27(2):153-158.

7. Songun I, Putter H, Kranenbarg EM, Sasako M, van de Velde CJ. Surgical treatment of gastric cancer: 15-year follow-up results of the randomized nationwide Dutch D1D2 trial. Lancet Oncol 2010;11(5):439-449.

8. Degiuli M, Sasako M, Ponti A, Calvo F. Survival results of a multicenter phase II study to evaluate D2 gastrectomy for gastric cancer. Br J Cancer. 2004;90(9): $1727-1732$. 
9. Macdonald JS, Smalley SR, Benedetti I, Hundahl SA, Estes NC, Stemmermann GN, Haller DG, Ajani JA, Gunderson LL, Jessup JM, Martenson JA. Chemoradiotherapy after surgery compared with surgery alone for adenocarcinoma of the stomach or gastroesophageal junction. N Engl J Med. 2001;345(10):725-730

10. Cunningham D, Allum WH, Stenning SP, Thompson JN, Van de Velde CJ, Nicolson M, Scarffe JH, Lofts FJ, Falk SI, Iveson TJ, Smith DB, Langley RE, Verma M, Weeden S, Chua YJ, MAGIC Trial Participants. Perioperative chemotherapy versus surgery alone for resectable gastroesophageal cancer. $\mathrm{N}$ Engl J Med. 2006;355(1):11-20.

11. UICC TNM. Classification of malignant tumours. 7th ed. NewYork: Wiley \& Liss; 2009

12. Han DS, Suh YS, Kong SH, Lee HJ, Choi Y, Aikou S, Sano T, Park BJ, Kim WH, Yang HK. Nomogram predicting long-term survival after $\mathrm{d} 2$ gastrectomy for gastric cancer. J Clin Oncol. 2012;30(31):3834-3840.

13. Roder JD, Böttcher K, Siewert JR, Busch R, Hermanek P, Meyer HJ. Prognostic factors in gastric carcinoma. Results of the German Gastric Carcinoma Study 1992. Cancer. 1993;72(7):2089-2097.

14. Bria E, De Manzoni G, Beghelli S, Tomezzoli A, Barbi S, Di Gregorio C, Scardoni M, Amato E, Frizziero M, Sperduti I, Corbo V, Brunelli M, Bersani S, Tortora G, Scarpa. A clinical-biological risk stratification model for resected gastric cancer: prognostic impact of Her2, Fhit, and APC expression status. Ann Oncol. 2013;24(3):693-701.

15. Marchet A, Mocellin S, Ambrosi A, Morgagni P, Garcea D, Marrelli D, Roviello F, de Manzoni G, Minicozzi A, Natalini G, De Santis F, Baiocchi L, Coniglio A, Nitti $\mathrm{D}$. The ratio between metastatic and examined lymph nodes ( $\mathrm{N}$ ratio) is an independent prognostic factor in gastric cancer regardless of the type of lymphadenectomy: results from an Italian multicentric study in 1853 patients. Ann Surg. 2007;245(4):543-552.

16. Wang W, Xu DZ, Li YF, Guan YX, Sun XW, Chen YB, Kesari R, Huang CY, Li W, Zhan YQ, Zhou ZW. Tumor-ratio-metastasis staging system as an alternative to the 7th edition UICC TNM system in gastric cancer after D2 resection--results of a single-institution study of 1343 Chinese patients. Ann Oncol. 2011; 22(9):2049-2056.

17. Wang J, Dang P, Raut CP, Pandalai PK, Maduekwe UN, Rattner DW, Lauwers GY, Yoon SS. Comparison of a lymph node ratio-based staging system with the 7th AJCC system for gastric cancer: analysis of 18,043 patients from the SEER database. Ann Surg. 2012; 255(3):478-485.

18. Xu DZ, Geng QR, Long ZJ, Zhan YQ, Li W, Zhou ZW, Chen YB, Sun XW, Chen G, Liu Q. Positive lymph node ratio is an independent prognostic factor in gastric cancer after $\mathrm{d} 2$ resection regardless of the examined number of lymph nodes. Ann Surg Oncol. 2009; 16(2):319-326.

19. Sun Z, Zhu GL, Lu C, Guo PT, Huang BJ, Li K, Xu Y, Li DM, Wang ZN, Xu $\mathrm{HM}$. The impact of $\mathrm{N}$-ratio in minimizing stage migration phenomenon in gastric cancer patients with insufficient number or level of lymph node retrieved: results from a Chinese mono-institutional study in 2159 patients. Ann Oncol. 2009; 20(5):897-905.

20. Sakuramoto S, Sasako M, Yamaguchi T, Kinoshita T, Fujii M, Nashimoto A Furukawa H, Nakajima T, Ohashi Y, Imamura H, Higashino M, Yamamura Y, Kurita A, Arai K, ACTS-GC Group: Adjuvant chemotherapy for gastric cancer with S-1, an oral fluoropyrimidine. N Engl J Med. 2007;357(18):1810-1820.

21. Bang YJ, Kim YW, Yang HK, Chung HC, Park YK, Lee KH, Lee KW, Kim YH,Noh SI, Cho JY, Mok YJ, Kim YH, Ji J, Yeh TS, Button P, Sirzén F, Noh SH, CLASSIC Trial Investigators: Adjuvant capecitabine and oxaliplatin for gastric cancer after D2 gastrectomy (CLASSIC): a phase 3 open-label, randomised controlled trial. Lancet. 2012;379(9813):315-321.

22. Wolmark N, Rockette H, Fisher B, Wickerham DL, Redmond C, Fisher ER, Jones J, Mamounas EP, Ore L, Petrelli NJ: The benefit of leucovorinmodulated fluorouracil as postoperative adjuvant therapy for primary colon cancer: results from national surgical adjuvant breast and bowel project protocol C-03. J Clin Oncol. 1993;11(10):1879-1887.

23. Nakajima T, Kinoshita T, Nashimoto A, Sairenji M, Yamaguchi T, Sakamoto J,Fujiya T, Inada T, Sasako M, Ohashi Y, National Surgical Adjuvant Study of Gastric Cancer Group: Randomized controlled trial of adjuvant uracil-tegafur versus surgery alone for serosa-negative, locally advanced gastric cancer. Br J Surg. 2007;94(12):1468-1476.

24. Extermann M, Overcash J, Lyman GH, Parr J, Balducci L. Comorbidity and functional status are independent in older cancer patients. J Clin Oncol. 1998;16(4):1582-1587.

25. Liu KH, Hung CY, Lu CH, Hsu JT, Yeh TS, Lin YC, Hung YS, Chou WC. Survival outcomes of geriatric patients with clinically resectable gastric cancer: to operate or not. J Surg Res. 2016;206(2):481-489.

26. Young J, Badgery-Parker T, Dobbins T, Jorgensen M, Gibbs P, Faragher I, et al. Comparison of ECOG/WHO performance status and ASA score as a measure of functional status. J Pain Sympt Manage. 2015;49(2):258-264.

27. GASTRIC (Global Advanced/Adjuvant Stomach Tumor Research International Collaboration) Group, Paoletti X, Oba K, Burzykowski T, Michiels S, Ohashi Y, Pignon JP, Rougier P, Sakamoto J, Sargent D, Sasako M, Van Cutsem E, Buyse M: Benefit of adjuvant chemotherapy for resectable gastric cancer: a meta-analysis. JAMA. 2010; 303(17):1729-1737.

28. Sun P, Xiang JB, Chen ZY: Meta-analysis of adjuvant chemotherapy after radical surgery for advanced gastric cancer. Br J Surg. 2009;96(1):26-33.

29. Chiu CF, Yang HR, Yang MD, Jeng LB, Sargeant AM, Yeh SP, Bai LY. The role of adjuvant chemotherapy for patients with stage II and stage III gastric adenocarcinoma after surgery plus D2 lymph node dissection: a real-world observation. Springerplus. 2016; 5(1):728

30. Sasako M, Sakuramoto S, Katai H, Kinoshita T, Furukawa H, Yamaguchi T, Nashimoto A, Fujii M, Nakajima T, Ohashi Y. Five-year outcomes of a randomized phase III trial comparing adjuvant chemotherapy with S-1 versus surgery alone in stage II or III gastric cancer. J Clin Oncol. 2011;29(33):4387-4393.

31. Noh SH, Park SR, Yang HK, Chung HC, Chung IJ, Kim SW, Kim HH, Choi JH, Kim HK, Yu W, Lee JI, Shin DB, Ji J, Chen JS, Lim Y, Ha S, Bang YJ. Adjuvant capecitabine plus oxaliplatin for gastric cancer after D2 gastrectomy (CLASSIC): 5-year follow-up of an open-label, randomised phase 3 trial. Lancet Oncol. 2014;15(12):1389-1396.

32. Diaz-Nieto R, Orti-Rodriguez R, Winslet M. Post-surgical chemotherapy versus surgery alone for resectable gastric cancer. Cochrane Database Syst Rev. 2013;9:CD008415.

33. Lee HY, Hwang IG, Park SE, Kim ML, Park SH, Kang JH, Kim YS, Oh SY, Won YW, Lee SI, Ji JH, Chi KC. Factors Influencing Clinicians' Choice of Adjuvant S-1 versus Capecitabine plus Oxaliplatin after Curative Gastrectomy in Patients with Gastric Cancer. J of Cancer. 2016;7(12):1171-1175.

34. Cancer Genome Atlas Research Network. Comprehensive molecular characterization of gastric adenocarcinoma. Nature. 2014;513(7517):202-209.

35. Sohn BH, Hwang JE, Jang HJ, Lee HS, Oh SC, Shim JJ, Lee KW, Kim EH, Yim SY, Lee SH, Cheong JH, Jeong W, Cho JY, Kim J, Chae J, Lee J, Kang WK, Kim $\mathrm{S}$, Noh SH, Ajani JA, Lee JS. Clinical significance of four molecular subtypes of gastric cancer identified by The Cancer Genome Atlas Project. Clin Cancer Res. 2017 Jul 26. doi: 10.1158/1078-0432.CCR-16-2211. 